\title{
Simulation of Soil Water and Heat Transfer under Subsurface Irrigation Considering Spatial Differences in Soil Hydraulic Properties
}

\author{
Kosuke HAMADA ${ }^{1 *}$, Yoshiyuki SHINOGI ${ }^{2}$, Tomoyuki TANIGUCHI ${ }^{2}$, \\ Hidetoshi MOCHIZUKI ${ }^{3}$ and Takeshi TAKEMURA ${ }^{1}$
}

\author{
${ }^{1}$ Western Region Agricultural Research Center, National Agriculture and Food Research \\ Organization, Zentsuji, Japan \\ ${ }^{2}$ Faculty of Agriculture, Kyushu University, Fukuoka, Japan \\ ${ }^{3}$ Western Region Agricultural Research Center, National Agriculture and Food Research \\ Organization, Fukuyama, Japan
}

\begin{abstract}
Enhanced irrigation efficiency is necessary to address water shortages, and precise estimation of soil water movement by simulation models is essential. Previous studies have suggested that soil hydraulic properties, which are important factors of soil water movement, differ spatially in the horizontal and vertical directions. However, most of studies have estimated soil water movement by considering soil hydraulic properties only along the soil profile. In the present study, we defined soil hydraulic conductivity and soil water retention as soil hydraulic properties, and conducted soil water movement simulations considering the spatial (horizontal and vertical) differences in soil hydraulic properties. The simulation model also estimated soil temperature to include water vapor transfer in the estimation of soil water movement. We validated the model by comparing simulated and observed results from a pot experiment, and comparing the soil water movement and soil temperature in two cases of applying the soil hydraulic properties: spatial application and vertical application. The results showed that the simulated soil temperature differed from the observed values due to the uniform application of thermal conductivity of soil. Our findings indicated that the differences in soil water movement between both cases increased with the number of irrigations.
\end{abstract}

Discipline: Agricultural Engineering

Additional key words: soil water distribution, hydraulic conductivity, soil water retention, water conservation

\section{Introduction}

Water shortages are among the most serious problems worldwide. Agriculture consumes more water than all other sectors including industry, with $65 \%$ of total agricultural water being used for irrigation (Shiklomanov \& Rodda 2003). Enhanced irrigation efficiency is necessary to reduce agricultural water usage, which can be achieved by precise estimations of soil water movement. Several studies have developed simulation models describing soil water movement (Bhatnagar \& Chauhan 2008, Miyamoto et al. 2017). ElNesr et al. (2014) applied a simulation model to subsurface irrigation to evaluate soil water distribution. In such models, the appropriate application of soil hydraulic properties such as soil hydraulic conductivity and soil water retention is important, as these are the principal factors determining soil water movement. Previous studies have applied soil hydraulic properties in different vertical layers (Horel et al. 2014, Zang et al. 2018).

Several studies have suggested that soil hydraulic properties differ spatially, however, in the horizontal and vertical directions. For example, root physical activities change the soil hydraulic properties (Bengough 2012, Gregory 2006, Scholl et al. 2014), and root distribution can alter soil water retention and soil water movement (Yuge et al. 2012). Moreover, Iqbal et al. (2005) evaluated the horizontal difference in saturated hydraulic properties in a field experiment. We hypothesized that considering the spatial differences in these properties would lead to

*Corresponding author: e-mail hamadak302@affrc.go.jp

Received 25 October 2018; accepted 22 August 2019. 
differences in the simulation results from what was obtained in previous studies. However, few studies have estimated soil water movement by considering the spatial difference in soil hydraulic properties.

In the present study, we defined soil hydraulic conductivity and soil water retention as soil hydraulic properties, and evaluated the differences in simulation results of subsurface irrigation between two cases with respect to soil hydraulic properties: spatial application and vertical application.

\section{Materials and methods}

\section{Development of the simulation model}

In subsurface-irrigated fields, the soil surface remains dry, and water vapor transfer exceeds liquid water movement (Hamada et al. 2015). To account for water vapor transfer, we introduced two equations describing the two-dimensional soil water movement and heat transfer (Phillip 1957) as follows:

$$
\begin{aligned}
\frac{\partial \theta}{\partial t}= & \frac{\partial}{\partial x}\left(D_{w} \frac{\partial \theta}{\partial x}\right)+\frac{\partial}{\partial z}\left(D_{w} \frac{\partial \theta}{\partial z}\right)+\frac{\partial}{\partial x}\left(D_{T} \frac{\partial T}{\partial x}\right) \\
& +\frac{\partial}{\partial z}\left(D_{T} \frac{\partial T}{\partial z}\right)+\frac{\partial K}{\partial z}+S+I r, \\
C_{v} \frac{\partial T}{\partial t}= & \frac{\partial}{\partial x}\left(\lambda \frac{\partial T}{\partial x}\right)+\frac{\partial}{\partial z}\left(\lambda \frac{\partial T}{\partial z}\right) \\
& +L \rho_{l}\left\{\frac{\partial}{\partial x}\left(D_{w v} \frac{\partial \theta}{\partial x}\right)+\frac{\partial}{\partial z}\left(D_{w v} \frac{\partial \theta}{\partial z}\right)\right\},
\end{aligned}
$$

where $\theta$ is the volumetric water content $\left(\mathrm{cm}^{3} \mathrm{~cm}^{-3}\right), D_{w}$ is the isothermal water diffusivity $\left(\mathrm{cm}^{2} \mathrm{~s}^{-1}\right), D_{T}$ is the thermal water diffusivity $\left(\mathrm{cm}^{2} \mathrm{~s}^{-1}{ }^{\circ} \mathrm{C}^{-1}\right), T$ is the soil temperature $\left({ }^{\circ} \mathrm{C}\right), \quad K$ is the unsaturated hydraulic conductivity ( $\left.\mathrm{cm} \mathrm{s}^{-1}\right), S$ is the soil water uptake by crop roots $\left(\mathrm{cm}^{3} \mathrm{~cm}^{-3} \mathrm{~s}^{-1}\right), I r$ is the water supply $\left(\mathrm{cm}^{3} \mathrm{~cm}^{-3} \mathrm{~s}^{-1}\right)$, $C_{v}$ is the volumetric heat capacity $\left(\mathrm{J} \mathrm{cm}^{-2}{ }^{\circ} \mathrm{C}^{-1}\right), \lambda$ is the thermal conductivity of soil $\left(\mathrm{W} \mathrm{cm}^{-1}{ }^{\circ} \mathrm{C}^{-1}\right), L$ is the latent heat of water vaporization $\left(\mathrm{J} \mathrm{g}^{-1}\right), \rho_{l}$ is water density (g $\left.\mathrm{cm}^{-3}\right)$, and $D_{w v}$ is the isothermal vapor diffusivity $\left(\mathrm{cm}^{2}\right.$ $\left.\mathrm{S}^{-1}\right)$.

Equations (1) and (2) calculated the volumetric water content and soil temperature in the model domain except on the soil surface.

To estimate the volumetric water content and soil temperature of the soil surface, we introduced Eqs. (3) and (4) as follows:

$$
E=L \rho_{l}\left(-D_{w} \frac{\partial \theta}{\partial z}-D_{T} \frac{\partial T}{\partial z}-K\right)
$$

$$
G=-\lambda \frac{\partial T}{\partial z}-L \rho_{l} D_{w v} \frac{\partial \theta}{\partial z},
$$

where $E$ is the latent heat flux in soil $\left(\mathrm{W} \mathrm{cm}^{-2}\right)$ and $G$ is the ground heat flux $\left(\mathrm{W} \mathrm{cm}^{-2}\right)$.

Equations (3) and (4) were solved to initially estimate the latent heat flux $E$ and sensible heat flux $H$ by using the following equations:

$$
\begin{aligned}
& E=\frac{\rho_{a} c_{p}}{\gamma} \frac{e_{s}-e_{a}}{r_{a}}, \\
& H=\rho_{a} c_{p} \frac{T_{s}-T_{a}}{r_{a}},
\end{aligned}
$$

where $\rho_{a}$ is the air density $\left(\mathrm{g} \mathrm{cm}^{-3}\right), c_{p}$ is the specific heat at constant air pressure $\left(\mathrm{J} \mathrm{g}^{-1}{ }^{\circ} \mathrm{C}^{-1}\right), \gamma$ is the psychrometer constant $\left(\mathrm{hPa}{ }^{\circ} \mathrm{C}^{-1}\right), e_{s}$ is the water vapor pressure on the soil surface (hPa), $e_{a}$ is the water vapor pressure at $T_{a}$ (hPa), $r_{a}$ is the diffusion resistance on the soil surface (s $\left.\mathrm{cm}^{-1}\right), T_{s}$ is the soil surface temperature $\left({ }^{\circ} \mathrm{C}\right)$, and $T_{a}$ is the air temperature $\left({ }^{\circ} \mathrm{C}\right)$.

The diffusion resistance on the soil surface $r_{a}$ was calculated using the following equation (Chamberlain 1968):

$$
r_{a}=\frac{\ln \left(z_{1} / z_{0}\right)}{\kappa u_{*}}+\frac{1}{S t u_{*}},
$$

where $z_{1}$ is the height at which wind velocity is measured (cm), $z_{0}$ is the roughness length $(\mathrm{cm}), \kappa$ is the Kármán constant $(-), u_{*}$ is the friction velocity $\left(\mathrm{cm} \mathrm{s}^{-1}\right)$, and $S t$ is the Stanton number (-).

The ground heat flux $G$ was estimated using the following equations:

$$
\begin{aligned}
& G=R_{n}-E-H, \\
& R_{n}=(1-a) R_{s}+L_{c}+L_{s k y}-L_{\text {soil }}, \\
& L_{p}=\varepsilon_{p} \sigma\left(T_{p}+273.16\right)^{4}, \\
& L_{\text {sky }}=\left(0.53+0.066 \sqrt{e_{a}}\right) \sigma\left(T_{a}+273.16\right)^{4}, \\
& L_{\text {soil }}=\varepsilon_{s} \sigma\left(T_{s}+273.16\right)^{4},
\end{aligned}
$$

where $R_{n}$ is the net radiation on the soil surface $\left(\mathrm{W} \mathrm{cm}{ }^{-2}\right.$ ), $a$ is the soil surface albedo, $R_{s}$ is the shortwave radiation on the soil surface ( $\left.\mathrm{W} \mathrm{cm}{ }^{-2}\right), L_{p}$ is the longwave radiation from the plant $\left(\mathrm{W} \mathrm{cm}^{-2}\right), \varepsilon_{p}$ is the emissivity of the plant, $\sigma$ is the Stefan-Boltzmann constant, $T_{p}$ is the plant temperature $\left({ }^{\circ} \mathrm{C}\right), L_{\text {sky }}$ is the longwave radiation from the sky $\left(\mathrm{W} \mathrm{cm}^{-2}\right)$, and $L_{\text {soil }}$ is the longwave radiation from the soil surface $\left(\mathrm{W} \mathrm{cm}^{-2}\right)$.

To estimate unsaturated hydraulic conductivity $K$ 
from the soil water retention curve and saturated hydraulic conductivity, we introduced the Mualem-van Genuchten model (Mualem 1976, van Genuchten 1980) as follows:

$$
\begin{aligned}
& \theta=\theta_{\text {res }}+\left(\theta_{\text {sat }}-\theta_{\text {res }}\right)\left(1+|\alpha h|^{n}\right)^{-m}, \\
& K=K_{\text {sat }} S_{e}^{l}\left[1-\left(1-S_{e}^{\frac{1}{m}}\right)^{m}\right]^{2}, \\
& S_{e}=\frac{\theta-\theta_{\text {res }}}{\theta_{\text {sat }}-\theta_{\text {res }}},
\end{aligned}
$$

where $\theta_{\text {res }}$ is the residual soil moisture content $\left(\mathrm{cm}^{3} \mathrm{~cm}^{-3}\right)$, $\theta_{\text {sat }}$ is the saturated soil moisture content $\left(\mathrm{cm}^{3} \mathrm{~cm}^{-3}\right), \alpha$ $\left(\mathrm{cm}^{-1}\right), m, n$, and $l(-)$ are empirical parameters, $h$ is the matric potential head (cm), $K_{\text {sat }}$ is the saturated hydraulic conductivity $\left(\mathrm{cm} \mathrm{s}^{-1}\right)$, and $S_{e}$ is the degree of saturation (-). The value of $m$ was determined by $m=1-1 / n$, and $l$ was set to 0.5 .

Parameters $\alpha$ and $n$ were determined by fitting the analytical volumetric water content described in Eq. (13) with the measured soil water retention curve.

We determined the model domain dimensions, horizontal and bottom boundaries, and water supply points from the pot experiment. The model domain dimensions assumed a width of $50 \mathrm{~cm}$ and a depth of 60 $\mathrm{cm}$, with the vertical and horizontal distances of each node at $1 \mathrm{~cm}$. We defined the horizontal boundary as 25 $\mathrm{cm}$ from the center, and the bottom boundary at a depth of $60 \mathrm{~cm}$. We applied no water and heat transfers at the horizontal boundaries, no heat transfer at the bottom boundary because the change in soil temperature decreases with depth, and free drainage at the bottom boundary. Water supply Ir corresponded to the amount of irrigation and was applied to a node at a depth of $50 \mathrm{~cm}$ from the center of the model domain.

This model required the input of the following observed values as parameters: shortwave radiation on soil surface $R_{s}$, water vapor pressure $e_{a}$, air temperature $T_{a}$, soil water uptake by crop roots $S$, plant temperature $T_{p}$, unsaturated hydraulic conductivity $K$, and water supply Ir. Soil water uptake by crop roots $S$ was determined using the transpiration volume (measured with a sap flow sensor) and volumetric root content; moreover, the transpiration volume was allocated to each node based on the node's volumetric root content. To estimate unsaturated hydraulic conductivity $K$, the saturated hydraulic conductivity and soil water retention curve were obtained. Observed temporal changes in volumetric water content $\theta$ and soil temperature $T$ were necessary for a comparison with simulated values. Those values were obtained from the pot experiment.

Isothermal water diffusivity $D_{w}$, isothermal vapor diffusivity $D_{w v}$, thermal water diffusivity $D_{T}$, volumetric heat capacity $C_{v}$, and thermal conductivity of soil $\lambda$ were inversely determined from the observed temporal changes in volumetric water content $\theta$ and soil temperature $T$. These parameters were applied uniformly in the model domain.

\section{Pot experiment}

To obtain input data for the simulation, we conducted a pot experiment in a greenhouse from 1 August to 23 October 2015. We set one acrylic container $(70 \mathrm{~cm}(\mathrm{H}) \times$ $50 \mathrm{~cm}(\mathrm{~W}) \times 10 \mathrm{~cm}(\mathrm{~L}))$ filled with non-fertilized soil and planted an okra seedling (Abelmoschus esculentus Moench) in the center of the container. The container was filled with Shimajiri Mahji soil, a red-clay soil that develops on coral limestone in Okinawa, Japan (Tokashiki 1993), and the soil dry density in the container was set to $1.25 \mathrm{~g} \mathrm{~cm}^{-3}$ based on information provided by the Okinawa Prefectural Agricultural Research Center. The sides of the container were covered with thermal insulation material (Styrofoam, thickness $=40 \mathrm{~mm}$ ) to prevent heat transfer and solar radiation from the sides. Figure 1 shows a schematic illustration of the measurements. Soil moisture and soil temperature sensors (5TE; METER Group, Pullman, USA) were installed at depths of $5,15,30$, and $40 \mathrm{~cm}$ in the center of the container. Four pyranometers (LI-200; LI-COR, USA) were placed on the soil surface, two of which were set at a distance of $5 \mathrm{~cm}$ horizontally from the crop, and the other two at a distance of $15 \mathrm{~cm}$. A temperature and humidity sensor (LR9501; HIOKI E. E. CORPORATION, Japan) was set at a height of $180 \mathrm{~cm}$ in the greenhouse. A sap flow sensor (SGA5-WS; Dynamax Inc., USA) was installed on the okra stem, and a tensiometer (DIK-8333; Daiki Rika Kogyo Co., Japan) was placed in the container at a depth of $25 \mathrm{~cm}$ to establish an irrigation schedule.

When the tensiometer showed a reading of $\mathrm{pF} 2.2$ (matric potential head of $158 \mathrm{~cm}$ ), subsurface irrigation was conducted for $30 \mathrm{~min}$. The amount of irrigation in one application was set to $35 \mathrm{~mm}(1.75 \mathrm{~L})$, determined based on the volumetric water content between field capacity (matric potential head of $64 \mathrm{~cm}$ ) and capillary cutting point (matric potential head of $1,000 \mathrm{~cm}$; Doorenbos \& Pruitt 1977) using the soil water retention curve at the beginning of the experiment. The retention curve was created using the Shimajiri Mahji soil contained in four $100 \mathrm{~mL}$ soil samplers (DIK-1801; Daiki Rika Kogyo Co., Japan) at the same soil dry density as that of the container. To promote plant growth, surface irrigation was conducted from 1 August to 26 September, and subsurface irrigation was conducted three times (first irrigation at 17:00 on 27 September, second irrigation at 
16:00 on 29 September, and third irrigation at 17:00 on 1 October) using an acrylic irrigation tube (diameter $\times$ length $=1.0 \mathrm{~cm} \times 10 \mathrm{~cm}$ ) placed at a depth of $50 \mathrm{~cm}$ in the center of the container. The irrigation tube was perforated with approximately 20 holes (2 $\mathrm{mm}$ in diameter). During the experiment, volumetric water content $\theta$, soil temperature $T$, shortwave radiation on soil surface $R_{s}$, air temperature $T_{a}$, and water vapor pressure $e_{a}$ in the greenhouse were measured at $10 \mathrm{~min}$. intervals. Transpiration volume and plant temperature $T_{p}$ were recorded at $1 \mathrm{~h}$ intervals.

At the end of the experiment, when the okra plant was approximately $40 \mathrm{~cm}$ in height, soil samples were collected using 100-mL soil samplers, except at points N3-D45 and N3-D55 because of the irrigation tube that was mounted between these two points (Fig. 1). Saturated hydraulic conductivity, soil water retention curves, and volumetric root content were evaluated for each soil sample. Saturated hydraulic conductivity was measured by the falling head method (Jury et al. 1991), and soil

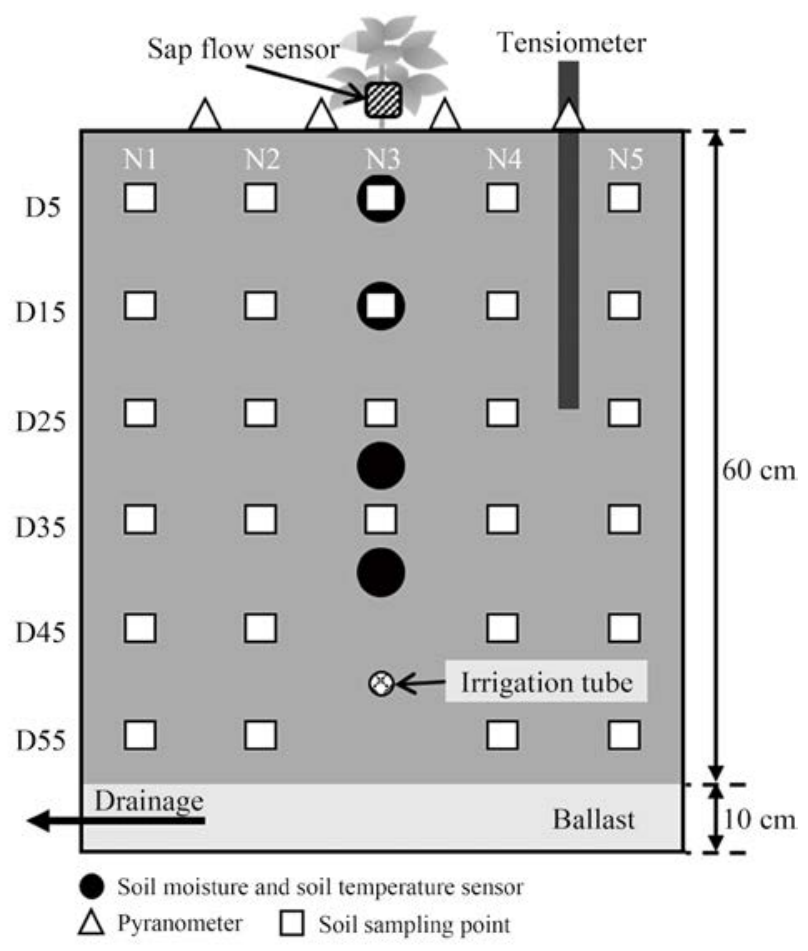

Fig. 1. Schematic diagram of measurements collected in an acrylic container to verify accuracy of the model The dimensions of the container were $70 \mathrm{~cm}(\mathrm{H}) \times 50$ $\mathrm{cm}(\mathrm{W}) \times 10 \mathrm{~cm}(\mathrm{~L})$. A temperature and humidity sensor was set at a height of $180 \mathrm{~cm}$ in the greenhouse. The horizontal and vertical distances of each soil sampling point were $10 \mathrm{~cm}$. D denotes the depth and $\mathrm{N}$ denotes a point on the surface. The container was covered by thermal insulation material except for the soil surface. water retention curves were generated by the hanging water column (matric potential head range: 1 to $158 \mathrm{~cm}$; Jury et al. 1991) and centrifuge methods (matric potential head range: 316 to 15,849 cm; Rao \& Singh 2012). After oven-drying the soil samples, the root volume was measured by placing the roots in a graduated cylinder containing water.

\section{Model validation and comparison of two cases}

We validated the model by comparing the simulated temporal changes in volumetric water content and soil temperature with the observed data. In the simulation, soil hydraulic properties were applied spatially as shown in Figure 2, with the spatial application being defined as Case 1. The data collected from 17:00 on 27 September to 17:00 on 2 October, during which time subsurface irrigation was conducted three times, were used. The initial volumetric water content and soil temperature were depth-dependent based on observed values. The observed shortwave radiation on soil surface $R_{s}$ was applied to the surface nodes spatially. We solved Eq. (7) under low wind conditions, with frictional velocity $u_{*}$ and wind velocity measurement height $z_{1}$ set to $0.1 \mathrm{~cm} \mathrm{~s}^{-1}$ and $180 \mathrm{~cm}$, respectively, based on previous research (Yuge et al. 2012).

Two application cases of soil hydraulic properties were analyzed: spatial application (Case 1) and vertical application in different soil layers (Case 2). In Case 2, we used soil hydraulic properties in the center of the container (N3-D5, N3-D15, N3-D25, and N3-D35), at the points where soil moisture and soil temperature sensors were installed. All data except soil hydraulic properties were the same as the model validation. We compared the temporal changes in volumetric water content and soil temperature at depths of $5,15,30$, and $40 \mathrm{~cm}$ in the center of the model domain, and soil water distribution between Case 1 and Case 2.

\section{Results}

\section{Pot experiment}

Figure 3 shows the temporal changes in air temperature in the greenhouse. Figure 4 shows the averaged shortwave radiation values on the soil surface. On 30 September and 1 October, the air temperature and averaged shortwave radiation were lower than on other days.

Roots were detected in 22 soil samples, whereas no roots were found in six soil samples. The volumetric root content in the soil samples ranged from 0.01 to $0.09 \%$.

Table 1 presents the soil hydraulic properties for the soil samples. As shown in Table 1, spatial differences 


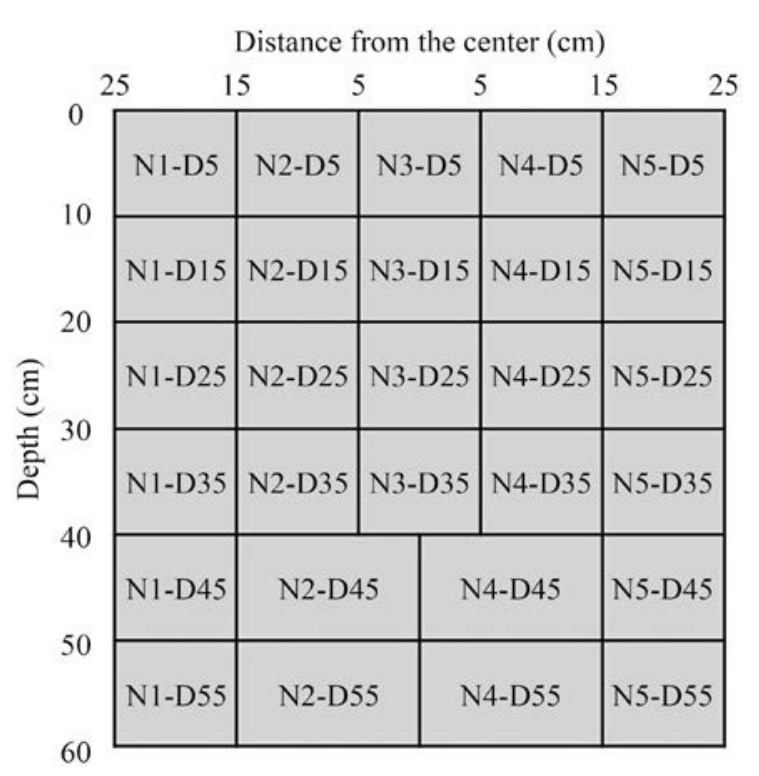

Fig. 2. Schematic representation of soil hydraulic properties application in the model domain

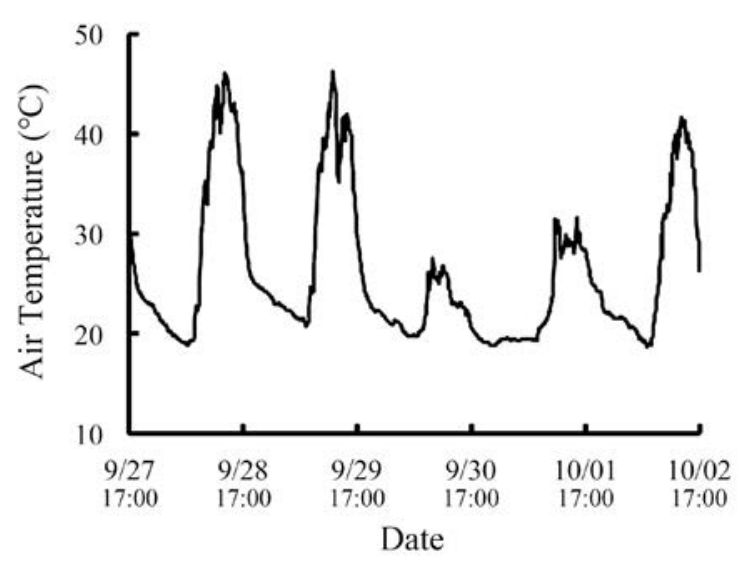

Fig. 3. Air temperature in the greenhouse during simulation period

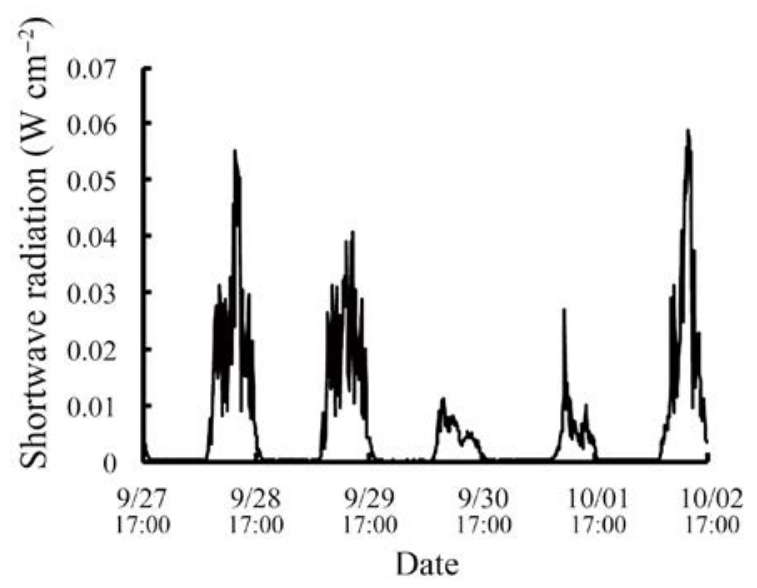

Fig. 4. Averaged shortwave radiation on the soil surface during simulation period were observed in the soil hydraulic properties.

\section{Model validation (Case 1 vs. observed values)}

Figure 5 shows the inversely determined parameters. We applied the inversely determined parameters uniformly and the soil hydraulic properties listed in Table 1 spatially in the model.

(1) Volumetric water content

Figure 6 shows the temporal changes in the simulated and observed volumetric water content. At depths of 5 and $15 \mathrm{~cm}$, the simulated volumetric water content followed a decreasing trend and was higher than the observed values. The simulated values at a depth of 30 cm exhibited an increasing trend, and tended to be higher than those for the observed volumetric water content. At a depth of $40 \mathrm{~cm}$, the simulated volumetric water content changed due to subsurface irrigation. The simulated values were slightly higher than the observed values after the third irrigation. The largest difference between the simulated values and observed values was less than 0.04 $\mathrm{cm}^{3} \mathrm{~cm}^{-3}$ at depths of 5, 15, and $30 \mathrm{~cm}$; at a depth of 40 $\mathrm{cm}$, the maximum difference of $0.10 \mathrm{~cm}^{3} \mathrm{~cm}^{-3}$ appeared after the third irrigation.

(2) Soil temperature

Figure 7 shows the temporal changes in the simulated and observed soil temperature values. At a depth of $5 \mathrm{~cm}$, the simulated result was similar to the observed value. At a depth of $15 \mathrm{~cm}$, the simulated soil temperature showed a similar trend in change to that of the observed result, except from 29 September to 2 October, when the simulated values were higher than the observed values. At depths of 30 and $40 \mathrm{~cm}$, the simulated values were different from the observed results. The simulated soil temperature showed little change before 17:00 on 29 September. After 17:00 on 29 September, the simulated values decreased; however, the decrease was slight compared with the observed results. The maximum differences between the simulated and observed values at depths of $5,15,30$, and $40 \mathrm{~cm}$ were $3.3,3.0,5.8$, and $6.7^{\circ} \mathrm{C}$, respectively.

\section{Comparison between Case 1 and Case 2}

Table 2 presents the soil hydraulic properties for Case 2. Figure 6 shows the temporal changes in volumetric water content in Case 1 and Case 2 . The volumetric water content in both cases was the same at depths of 5 and $15 \mathrm{~cm}$, and the maximum difference between both cases was smaller than $0.001 \mathrm{~cm}^{3} \mathrm{~cm}^{-3}$ at these depths. At depths of 30 and $40 \mathrm{~cm}$, the difference between both cases appeared after the third irrigation, and the maximum difference at these depths was 0.03 $\mathrm{cm}^{3} \mathrm{~cm}^{-3}$. Figure 7 shows the temporal changes in soil 
Table 1. Parameters of the Mualem-van Genuchten model for Case 1

\begin{tabular}{|c|c|c|c|c|c|c|c|c|}
\hline No. & $K_{\text {sat }}$ & $\theta_{\text {res }}$ & $\theta_{\text {sat }}$ & $\alpha$ & $n$ & l & $\rho_{d}$ & Application depth \\
\hline N1-D5 & $1.92 \times 10^{-6}$ & 0.050 & 0.556 & 0.074 & 1.175 & 0.5 & 1.07 & \multirow{5}{*}{$0-10 \mathrm{~cm}$} \\
\hline N2-D5 & $1.03 \times 10^{-5}$ & 0.050 & 0.552 & 0.033 & 1.147 & 0.5 & 1.07 & \\
\hline N3-D5 & $1.18 \times 10^{-3}$ & 0.070 & 0.521 & 0.048 & 1.143 & 0.5 & 1.10 & \\
\hline N4-D5 & $3.95 \times 10^{-4}$ & 0.110 & 0.598 & 0.092 & 1.177 & 0.5 & 0.98 & \\
\hline N5-D5 & $3.39 \times 10^{-6}$ & 0.050 & 0.564 & 0.061 & 1.147 & 0.5 & 1.00 & \\
\hline N1-D15 & $2.71 \times 10^{-2}$ & 0.076 & 0.539 & 0.093 & 1.179 & 0.5 & 0.88 & \multirow{5}{*}{$10-20 \mathrm{~cm}$} \\
\hline N2-D15 & $5.13 \times 10^{-2}$ & 0.050 & 0.510 & 0.054 & 1.171 & 0.5 & 0.83 & \\
\hline N3-D15 & $3.57 \times 10^{-2}$ & 0.060 & 0.565 & 0.079 & 1.183 & 0.5 & 0.92 & \\
\hline N4-D15 & $2.03 \times 10^{-2}$ & 0.050 & 0.496 & 0.079 & 1.151 & 0.5 & 0.92 & \\
\hline N5-D15 & $6.08 \times 10^{-3}$ & 0.050 & 0.539 & 0.140 & 1.142 & 0.5 & 0.93 & \\
\hline N1-D25 & $1.76 \times 10^{-2}$ & 0.088 & 0.580 & 0.154 & 1.173 & 0.5 & 0.92 & \multirow{5}{*}{$20-30 \mathrm{~cm}$} \\
\hline N2-D25 & $3.56 \times 10^{-3}$ & 0.120 & 0.528 & 0.059 & 1.214 & 0.5 & 0.92 & \\
\hline N3-D25 & $1.29 \times 10^{-1}$ & 0.050 & 0.601 & 0.061 & 1.181 & 0.5 & 0.91 & \\
\hline N4-D25 & $1.41 \times 10^{-1}$ & 0.050 & 0.572 & 0.097 & 1.171 & 0.5 & 0.90 & \\
\hline N5-D25 & $3.57 \times 10^{-3}$ & 0.100 & 0.650 & 0.048 & 1.304 & 0.5 & 0.91 & \\
\hline N1-D35 & $5.38 \times 10^{-3}$ & 0.072 & 0.603 & 0.119 & 1.194 & 0.5 & 0.88 & \multirow{5}{*}{$30-40 \mathrm{~cm}$} \\
\hline N2-D35 & $1.16 \times 10^{-1}$ & 0.075 & 0.621 & 0.063 & 1.228 & 0.5 & 0.91 & \\
\hline N3-D35 & $7.92 \times 10^{-2}$ & 0.050 & 0.472 & 0.098 & 1.143 & 0.5 & 0.81 & \\
\hline N4-D35 & $1.64 \times 10^{-2}$ & 0.065 & 0.565 & 0.095 & 1.170 & 0.5 & 0.95 & \\
\hline N5-D35 & $2.67 \times 10^{-2}$ & 0.050 & 0.453 & 0.087 & 1.151 & 0.5 & 0.84 & \\
\hline N1-D45 & $2.93 \times 10^{-2}$ & 0.065 & 0.604 & 0.099 & 1.145 & 0.5 & 1.02 & \multirow{4}{*}{$40-50 \mathrm{~cm}$} \\
\hline N2-D45 & $3.51 \times 10^{-2}$ & 0.050 & 0.509 & 0.093 & 1.116 & 0.5 & 0.97 & \\
\hline N4-D45 & $7.09 \times 10^{-3}$ & 0.059 & 0.597 & 0.088 & 1.150 & 0.5 & 1.00 & \\
\hline N5-D45 & $1.91 \times 10^{-2}$ & 0.050 & 0.535 & 0.080 & 1.112 & 0.5 & 1.09 & \\
\hline N1-D55 & $2.66 \times 10^{-2}$ & 0.050 & 0.548 & 0.086 & 1.116 & 0.5 & 1.05 & \multirow{4}{*}{$50-60 \mathrm{~cm}$} \\
\hline N2-D55 & $4.44 \times 10^{-5}$ & 0.050 & 0.591 & 0.088 & 1.124 & 0.5 & 1.02 & \\
\hline N4-D55 & $3.60 \times 10^{-5}$ & 0.050 & 0.589 & 0.060 & 1.120 & 0.5 & 1.05 & \\
\hline N5-D55 & $6.01 \times 10^{-5}$ & 0.050 & 0.553 & 0.042 & 1.128 & 0.5 & 1.08 & \\
\hline
\end{tabular}

$K_{\text {sat }}$ is the saturated hydraulic conductivity $\left(\mathrm{cm} \mathrm{s}^{-1}\right), \theta_{\text {res }}$ is the residual soil moisture $\left(\mathrm{cm}^{3} \mathrm{~cm}^{-3}\right), \theta_{\text {sat }}$ is the saturated soil moisture $\left(\mathrm{cm}^{3} \mathrm{~cm}^{-3}\right), \alpha\left(\mathrm{cm}^{-1}\right), n$ and $l(-)$ are the empirical parameters, and $\rho_{d}$ is the dry soil density $\left(\mathrm{g} \mathrm{cm}^{-3}\right)$.
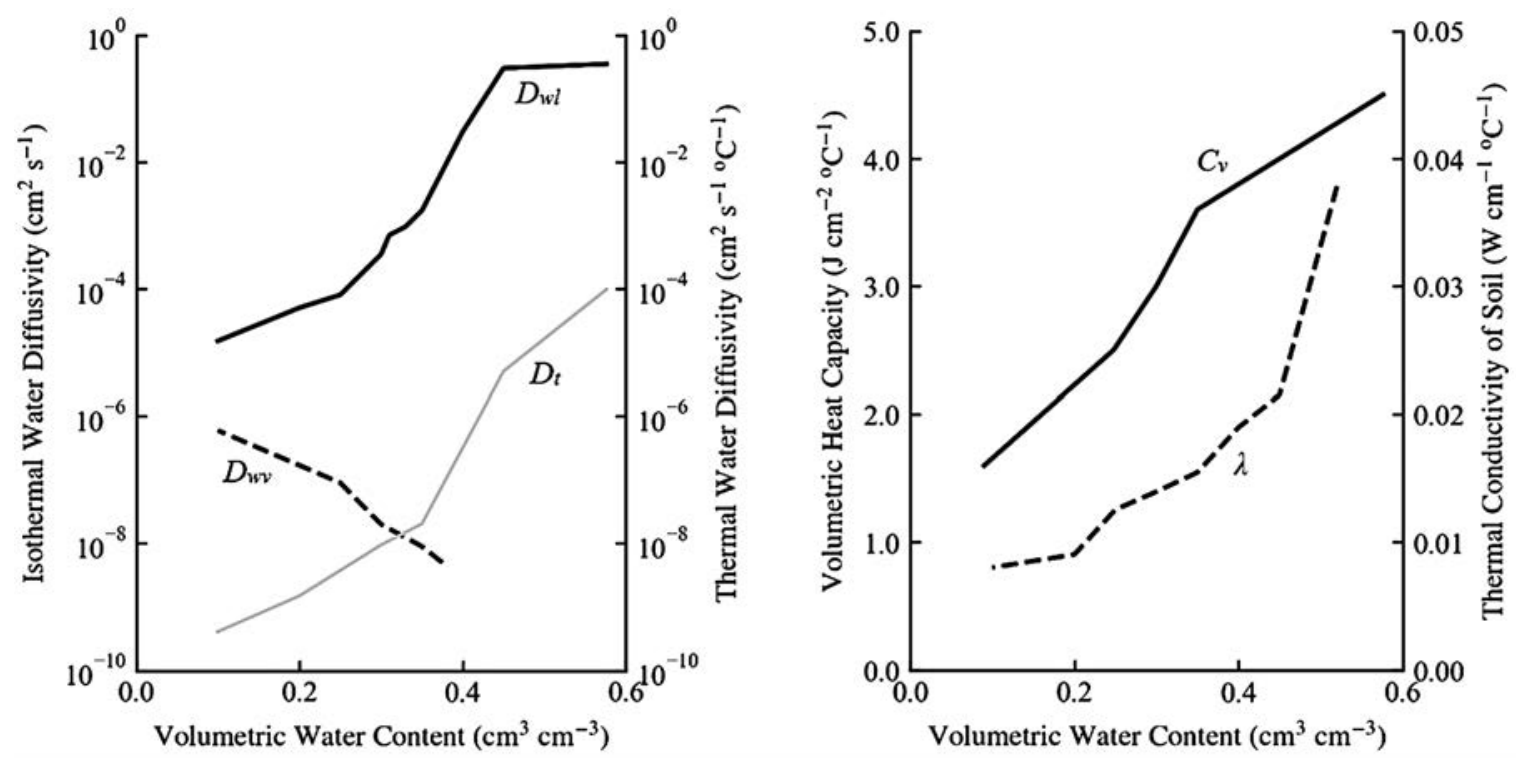

Fig. 5. Inversely determined $D_{w}, D_{w v}, D_{T}, C_{v}$, and $\lambda$

$D_{w}$ is the isothermal water diffusivity $\left(\mathrm{cm}^{2} \mathrm{~s}^{-1}\right), D_{w v}$ is the isothermal vapor diffusivity $\left(\mathrm{cm}^{2} \mathrm{~s}^{-1}\right), D_{T}$ is the thermal water diffusivity $\left(\mathrm{cm}^{2} \mathrm{~s}^{-1}{ }^{\circ} \mathrm{C}^{-1}\right), C_{v}$ is the volumetric heat capacity $\left(\mathrm{J} \mathrm{cm}^{-2}{ }^{\circ} \mathrm{C}^{-1}\right)$, and $\lambda$ is the thermal conductivity of soil $\left(\mathrm{W} \mathrm{cm}^{-1}{ }^{\circ} \mathrm{C}^{-1}\right)$. 
temperature in Case 1 and Case 2. The soil temperature in both cases was almost same at depths of 5-40 cm.

The difference in soil water distribution between Case 1 and Case 2 was calculated at $1 \mathrm{~h}$ and one day after the first, second, and third irrigations (Fig. 8). And $1 \mathrm{~h}$ after the first and second irrigations, the difference in soil water distribution in Case 1 was higher below the irrigation tube, whereas in Case 2, it was higher above the irrigation tube. One day after the first and second irrigations, soil water distribution was higher for Case 2 (a) $5 \mathrm{~cm}$

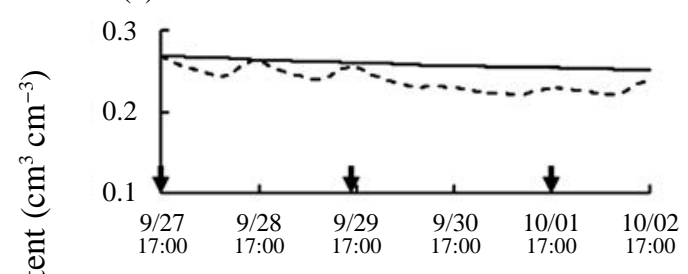

(c) $30 \mathrm{~cm}$

望

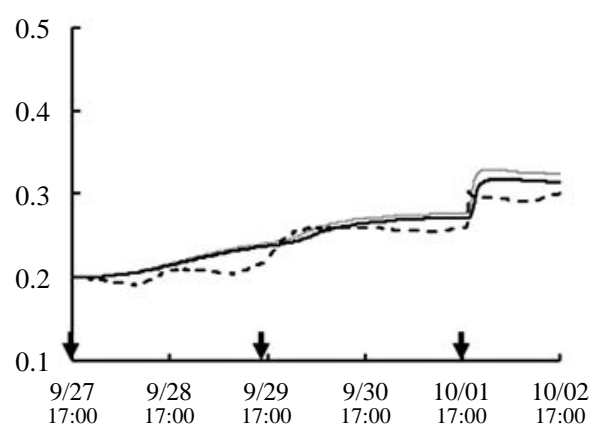

(b) $15 \mathrm{~cm}$

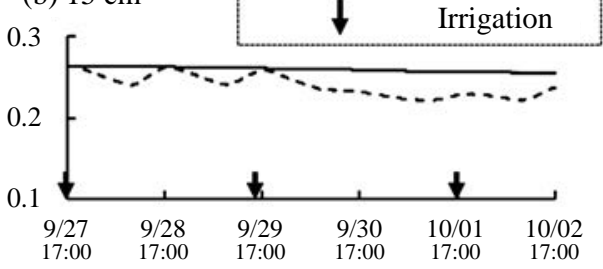

(d) $40 \mathrm{~cm}$

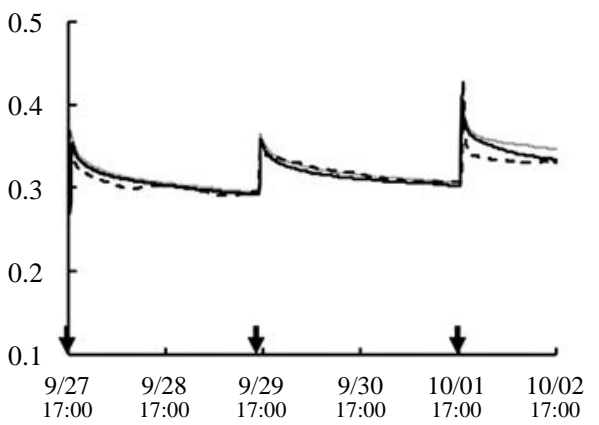

Date

Fig. 6. Temporal changes in volumetric water content at different soil depths

Case 1 is the spatial application of soil hydraulic properties and Case 2 is the vertical application. The amount of irrigation per application was $35 \mathrm{~mm}(1.75 \mathrm{~L})$.

(a) $5 \mathrm{~cm}$

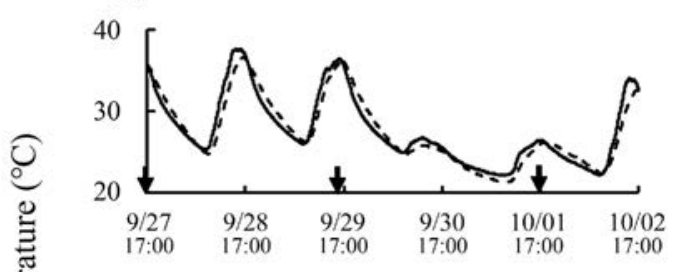

(c) $30 \mathrm{~cm}$

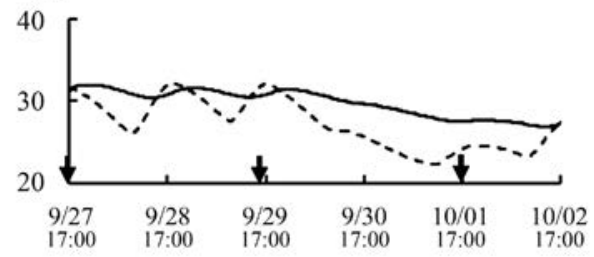

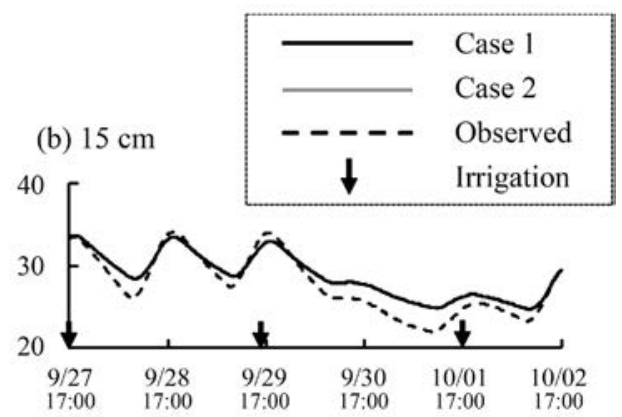

(d) $40 \mathrm{~cm}$

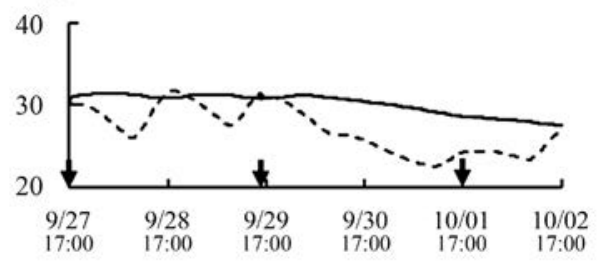

Date

Fig. 7. Temporal changes in soil temperature at different soil depths

Figure 6 defines Case 1, Case 2, and the amount of irrigation per application. 
than for Case 1, while the difference between both cases decreased. The value in Case 2 was higher around the irrigation tube $1 \mathrm{~h}$ after the third irrigation, and it appeared approximately $15 \mathrm{~cm}$ away from the irrigation tube. The difference in soil water distribution (reaching maximum of $0.03 \mathrm{~cm}^{3} \mathrm{~cm}^{-3}$ ) detected one day after the third irrigation extended over a wider area, within about $25 \mathrm{~cm}$ from the irrigation tube.

\section{Discussion}

\section{Model validation (Case 1 vs. observed values)}

As shown in Figure 6, the reduced amount of the simulated volumetric water content at depths of 5 and 15 $\mathrm{cm}$ was less than the observed values. The simulated values were considered to predict a decreasing trend like the observed values, but tended to overestimate the volumetric water content. At a depth of $30 \mathrm{~cm}$, the simulated results reflected the observed values, and the simulated values at a depth of $40 \mathrm{~cm}$ showed close similarity to the observed result. In contrast, the maximum difference between the simulated and observed values was greater at $40 \mathrm{~cm}$ than at other depths. The increase in simulated volumetric water content due to the third irrigation appeared $10 \mathrm{~min}$. earlier than the observed values, and accounted for most of the difference.

The difference between the simulated and observed soil temperature increased with depth, and the difference was large after 17:00 on 29 September (Fig. 7). The temporal changes in air temperature and shortwave radiation on the soil surface between 30 September and 1 October were smaller compared with the values reported for other days (Figs. 3 and 4). This suggested that the difference occurs under conditions of relatively low air temperature and shortwave radiation on the soil surface. In addition, at depths of 30 and $40 \mathrm{~cm}$, the simulated and observed volumetric water content increased with the increase in irrigation frequency (Fig. 6), which in turn increased thermal conductivity of soil $\lambda$. In our model, we applied the same property of thermal conductivity of soil $\lambda$ (Fig. 5) in the whole model domain. Thus, the uniform application might have caused the difference between the estimated and observed soil temperature.

The simulated soil temperature at depths shallower than $15 \mathrm{~cm}$ and the simulated volumetric water content at depths deeper than $30 \mathrm{~cm}$ changed in accordance with the observed values. However, both values at other depths differed from the observed values, and future studies should aim to improve the estimation accuracy at those depths.

\section{Comparison between Case 1 and Case 2}

The difference in soil hydraulic application was not sufficient to affect the temporal change in soil temperature at all depths, because the application of soil thermal conductivity $\lambda$ was identical in both cases (Fig. 7).

As shown in Figure 6, the temporal change in volumetric water content between Case 1 and Case 2 was almost the same during the experimental period at depths of 5 and $15 \mathrm{~cm}$. However, at depths of 30 and $40 \mathrm{~cm}$, the difference between both cases appeared after the third irrigation. The differences in the soil water distribution increased with the number of irrigations (Fig. 8). This would be apparent in the differences of the soil hydraulic properties. For example, as shown in Tables 1 and 2, the saturated hydraulic conductivities in Case 2 were higher than in Case 1, with the exceptions of N3-D5, N2-D15, N3-D15, N3-D25, N4-D25, N2-D35, and N3-D35. This implies that soil hydraulic conductivity is one of the factors accounting for the difference in soil water distribution.

These results indicated that the difference between both cases mainly appeared in soil water distribution.

\section{Conclusion}

In the present study, we conducted soil water and heat transfer simulation under two cases with differing soil hydraulic properties: spatial application and vertical application. The soil temperature results revealed that values for the two cases at depths of 30 and $40 \mathrm{~cm}$ were different from the observed values. This difference may have been due to the uniform application of thermal conductivity of soil in the model. The difference between

Table 2. Parameters of the Mualem-van Genuchten model for Case 2

\begin{tabular}{ccccccccc}
\hline \hline No. & $K_{\text {sat }}$ & $\theta_{\text {res }}$ & $\theta_{\text {sat }}$ & $\alpha$ & $n$ & $l$ & $\rho_{d}$ & Application depth \\
\hline N3-D5 & $1.18 \times 10^{-3}$ & 0.070 & 0.521 & 0.048 & 1.143 & 0.5 & 1.10 & $0-10 \mathrm{~cm}$ \\
N3-D15 & $3.57 \times 10^{-2}$ & 0.060 & 0.565 & 0.079 & 1.183 & 0.5 & 0.92 & $10-20 \mathrm{~cm}$ \\
N3-D25 & $1.29 \times 10^{-1}$ & 0.050 & 0.601 & 0.061 & 1.181 & 0.5 & 0.91 & $20-30 \mathrm{~cm}$ \\
N3-D35 & $7.92 \times 10^{-2}$ & 0.050 & 0.472 & 0.098 & 1.143 & 0.5 & 0.81 & $30-60 \mathrm{~cm}$ \\
\hline
\end{tabular}

Table 1 defines $K_{\text {sat }}, \theta_{\text {res }}, \theta_{\text {sat }}, \alpha, n, l$, and $\rho_{d}$. 
1 hour after 1 st irrigation

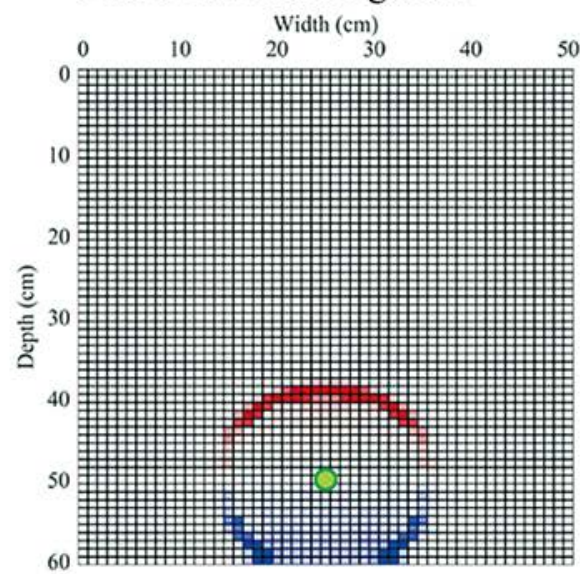

(a) 18:00 September 27

1 hour after 2 nd irrigation

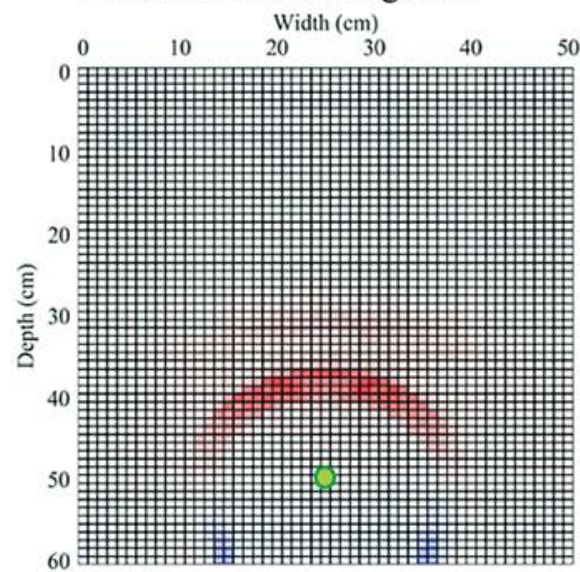

(c) 17:00 September 29

1 hour after 3rd irrigation

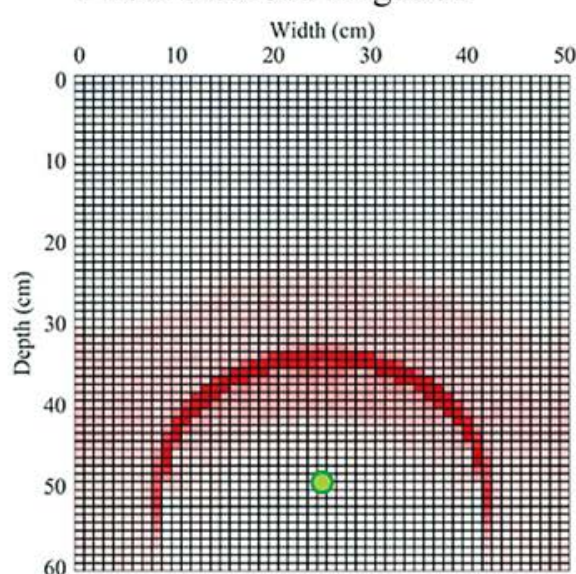

(e) 18:00 October 1
1 day after 1 st irrigation

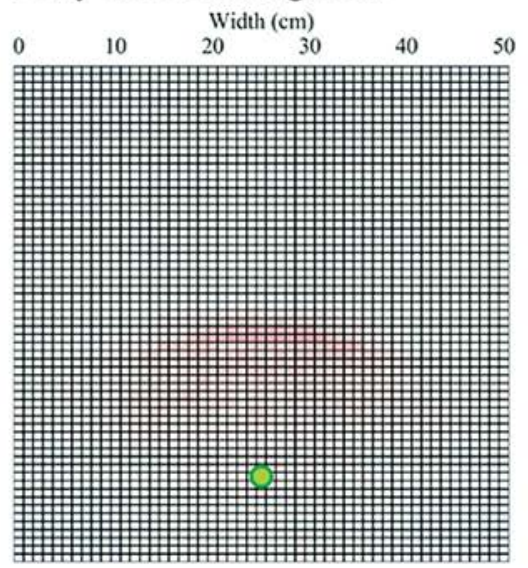

(b) 17:00 September 28

1 day after 2 nd irrigation

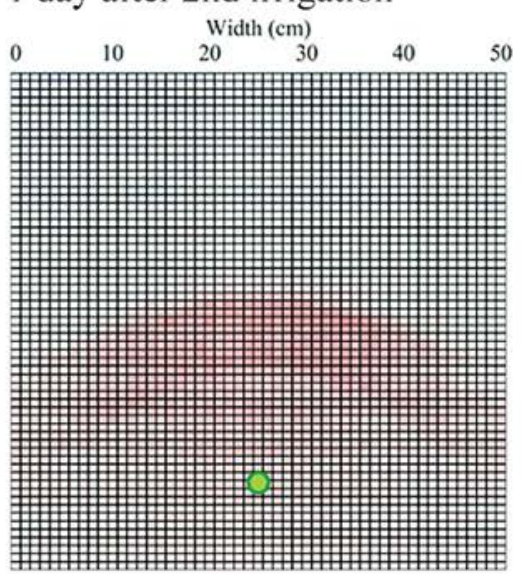

(d) 16:00 September 30

1 day after 3rd irrigation

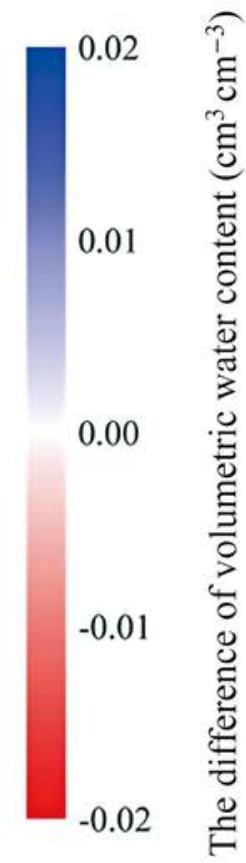

(f) 17:00 October 2

Irrigation tube

Fig. 8. The difference in soil water distribution between Case 1 and Case 2

Figure 6 defines Case 1 and Case 2. The difference was calculated by subtracting the result of Case 2 from the result of Case 1. Blue indicates higher volumetric water content under Case 1 than under Case 2, whereas red indicates that the value is higher in Case 2 than in Case 1. 
both cases appeared in soil water distribution, and the difference due to the application of soil hydraulic properties increased with the number of irrigations. The present results were obtained for clayey soil under subsurface irrigation conditions, and are not applicable to other soil types and irrigation methods (e.g., surface irrigation) as the spatial difference in soil hydraulic properties affects soil water movement differently. Therefore, to broaden our understanding of the effects of spatial soil hydraulic properties on soil water movement, more studies and data accumulation are necessary.

\section{Acknowledgments}

This work was supported by the Japanese Society for the Promotion of Science, Grants-in-Aid for Scientific Research (JSPS KAKENHI; Grant Number JP15J03307). The authors are grateful to Hisayoshi Inoue, Ph.D., for his helpful comments on this work.

\section{References}

Bengough, A. G. (2012) Water dynamics of the root zone: rhizosphere biophysics and its control on soil hydrology. Vadose Zone J., 11. https://doi.org/10.2136/vzj2011.0111.

Bhatnagar, P. R. \& Chauhan, H. S. (2008) Soil water movement under a single surface trickle source. Agric. Water Manag., 95, 799-808.

Chamberlain, A. C. (1968) Transport of gases to and from surface with bluff and wave-like roughness elements. Q. J. Roy. Meteor. Soc., 94, 318-332.

Doorenbos, J. \& Pruitt, W. O. (1977) Guidelines for predicting crop water requirements. Food and Agriculture Organization (FAO) Irrigation and Drainage Paper 24, FAO, Rome.

El-Nesr, M. N. et al. (2014) HYDRUS simulations of the effects of dual-drip subsurface irrigation and a physical barrier on water movement and solute transport in soils. Irrg. Sci., 32, $111-125$

Gregory, P. J. (2006) Plant roots: growth, activity and interactions with soil. Blackwell, London.

Hamada, K. et al. (2015) Evaluation of the water saving effect of subsurface irrigation in Shimajiri Mahji soil fields. J. Food Agric. Environ., 13, 54-59.

Horel, A. et al. (2014) Transport of iodide in structured clayloam soil under maize during irrigation experiments analyzed using HYDRUS model. Biologia, 69, 1531-1538.

Iqbal, J. et al. (2005) Spatial variability analysis of soil physical properties of Alluvial soils. Soil Sci. Soc. Am. J., 69, 1338-1350.

Jury, W. A. et al. (1991) Soil physics, 5th edition. John Wiley \& Sons, New York.

Miyamoto, T. et al. (2017) Modelling soil water flow in plastic-mulched ridges in humid areas using HYDRUS. J. Jpn. Soc. Soil Phys., 136, 3-14 [In Japanese with English summary].

Mualem, Y. (1976) A new model for predicting the hydraulic conductivity of unsaturated porous media. Water Resour. Res., 12, 513-522.

Phillip, J. R. (1957) Evaporation, and moisture and heat fields in the soil. J. Meteorology, 14, 354-366.

Rao, B. H. \& Singh, D. N. (2012) Establishing soil-water characteristic curve and determining unsaturated hydraulic conductivity of kaolin by ultracentrifugation and electrical measurements. Can. Geotech. J., 49, 1369-1377.

Scholl, P. et al. (2014) Root induced changes of effective 1D hydraulic properties in a soil column. Plant Soil, 381, 193-213.

Shiklomanov, I. A. \& Rodda, J. C. (2003) World water resources at the beginning of the twenty-first century. Cambridge University Press, Cambridge, UK.

Tokashiki, Y. (1993) The characteristic properties of the Shimajiri Mahji and Jahgaru soils in Okinawa prefecture. Pedologist, 37, 99-112 [In Japanese].

van Genuchten, M. T. (1980) A closed-form equation for predicting the hydraulic conductivity of unsaturated soils. Soil Sci. Soc. Am. J., 44, 892-898.

Yuge, K. et al. (2012) Effect of crop root on soil water retentivity and movement. Am. J. Plant Sci., 3, 1782-1787.

Zhang, Y. L. et al. (2018) Simulation of soil water flow and heat transport in drip irrigated potato field with raised beds and full plastic-film mulch in a semiarid area. Agric. Water Manag., 209, 178-187. 